\title{
Computed tomography assessment of Apert syndrome
}

\section{Avaliação da síndrome de Apert por meio da tomografia computadorizada}

\author{
Marco Antônio Portela Albuquerque* \\ Marcelo Gusmão Paraíso Cavalcanti**
}

\begin{abstract}
Apert syndrome, or acrocephalosyndactyly type I, is a craniofacial dysostosis, an autosomal dominant condition characterized by severe developmental disturbances of the craniofacial region including bilateral coronal synostosis associated with midface hypoplasia, exophthalmia, hypertelorism, and symmetric syndactyly of the hands and feet. The aim of this study is to assess the clinical and computed tomography imaging patterns of non-operated patients with Apert syndrome, correlating the bone abnormalities of the cranium, face and the skull base. The study population consisted of 5 patients with Apert syndrome. As part of the craniofacial assessment of the imaging center's routine, all patients underwent clinical evaluation and CT (computed tomograph) exam. Three-dimensional images were generated from helical CT scans, using an independent workstation, to evaluate the craniofacial abnormalities of the syndrome. Clinical exam determined that syndactyly of the hands and feet, pseudocleft in the midline palate and midface hypoplasia were features observed in all of the Apert patients. 3DCT showed that some abnormalities such as bilateral coronal synostosis, calvarial midline defect and reduction in the antero-posterior dimension of the anterior, medial and posterior cranial fossae were present in all cases. In conclusion, the correlation of clinical and $\mathrm{CT}$ imaging findings can be useful to assess the main features observed in Apert patients, improving the criteria for examining the patient and diagnosing this condition, and contributing to the therapeutic planning and surgical follow-up.
\end{abstract}

DESCRIPTORS: Tomography; X-ray computed; Skull; Acrocephalosyndactylia.

RESUMO: A síndrome de Apert, também denominada acrocefalossindactilia tipo I, é uma disostose craniofacial de caráter hereditário autossômico dominante. Caracteriza-se por distúrbio severo de desenvolvimento na região craniofacial, incluindo sinostose bilateral da sutura coronal, associada a hipoplasia maxilar, exoftalmia, hipertelorismo e sindactilia simétrica de mãos e pés. O presente trabalho tem por objetivo o estudo de pacientes portadores da sindrome de Apert, não-operados, correlacionando os achados clínicos com os obtidos por meio da tomografia computadorizada (TC). Foram analisados 5 pacientes, sendo todos submetidos ao exame clínico e à tomografia computadorizada. Reconstruções tridimensionais (3D-TC) foram obtidas a partir de um tomógrafo helicoidal, utilizando uma estação de trabalho independente, para avaliação das alterações craniofaciais provocadas pela sindrome. A análise clínica determinou que sindactilia de mãos e pés, pseudofenda na linha média do palato e hipoplasia da maxila são achados observados em todos os pacientes. A 3D-TC mostrou que algumas alterações como sinostose bilateral das suturas coronais, defeito na linha média da calvária e redução na dimensão ântero-posterior da fossa craniana anterior, média e posterior estavam presentes em todos os casos. A combinação e correlação entre os achados clínicos e os observados na 3D-TC pode ser útil na avaliação das alterações observadas na síndrome de Apert, possibilitando melhora no estudo do paciente e promovendo informações importantes no diagnóstico, planejamento terapêutico e acompanhamento cirúrgico.

DESCRITORES: Tomografia computadorizada por raios X; Crânio; Acrocefalossindactilia.

\section{INTRODUCTION}

Apert syndrome, or acrocephalosyndactyly type I, is a craniofacial dysostosis first described by Apert in $1906^{1}$. It is an autosomal dominant condition characterized by severe developmental disturbances of the craniofacial region including craniosynostosis of any suture of the cranium (especially the coronal) and/or skull base associated with midface hypoplasia, exophthalmia, hypertelorism, symmetric syndactyly of the hands and feet, and other systemic malformations ${ }^{2,3,4,10}$. According to
Cohen et al. ${ }^{2}$ (1992) the incidence of Apert syndrome is approximately one in 50,000 births and most cases occur randomly, corresponding to $4.5 \%$ of all craniosynostosis.

The infant Apert skull is characterized at birth by premature fusion of the coronal sutures and by a wide calvarial midline defect extending from the glabella to the posterior fontanelle ${ }^{3,9}$. Other abnormalities include: significant reduction of the cranial length (brachicephaly), an increase of its

\footnotetext{
* Master's Degree Student of Oral Diagnosis; **Professor, Department of Radiology - School of Dentistry, University of São Paulo.
} 
height (turricephaly), while the breadth is found to be within normal limits or slightly increased ${ }^{3,7,8}$.

The oral cavity of Apert patients is also characteristic of the syndrome. The findings include a reduced size of the maxilla, especially in the antero-posterior dimension, resulting in tooth crowding and an anterior open-bite of the upper jaw ${ }^{8}$. The mandible is within normal size and shape, and simulates a pseudoprognathism. Cleft soft palate or bifid uvula is found in approximately $75 \%{ }^{8}$. Dental anomalies including impacted teeth, delayed eruption, ectopic eruption, supernumerary teeth, congenitally missing teeth, and thick gingiva are common characteristics ${ }^{9}$. A Byzantine-arch shaped palate with lateral swellings is observed in almost all patients and becomes more pronounced with age $^{8}$. The bilateral palatal swellings produce a deep median groove, which can lead to a misdiagnosis of cleft palate ${ }^{12,14}$.

Computed tomography (CT) has been shown to be a very sensitive method to evaluate craniofacial anomalies such as Apert syndrome $e^{9,15,16}$. The diagnostic value of three-dimensional reconstructed images by computed tomography (3DCT) is particularly high in individuals with complex craniofacial deformities, and in patients with congenital malformations as well ${ }^{7}$. These images are routinely used by most medical centers to define the individual aspects of complex anatomy, plan interventions and follow results of craniofacial anomalies ${ }^{16}$. 3D-CT imaging is the method of choice for understanding the pathologic morphology of Apert patients and in the preparation for craniofacial surgery ${ }^{15}$.

The purpose of this study is to assess the clinical and CT imaging patterns of non-operated patients with Apert syndrome, correlating the abnormalities such as bone abnormalities of the face, cranium and the skull base.

\section{MATERIAL AND METHODS}

The study population consisted of 5 patients with Apert syndrome - 4 males and 1 female. The ages ranged from 2 to 4 years with a mean of 3.5 years.

As part of the craniofacial assessment of the imaging center's routine, all patients underwent a clinical evaluation and were submitted to conventional radiographs of the hands and feet, and lateral and frontal skull radiographs. Subsequently, the patients underwent axial CT examination using Toshiba S/X Press (Toshiba Medical System, Tustin, CA, USA), beginning superior to the vertex and extending inferiorly to below the mandible. High resolution contiguous $3 \mathrm{~mm}$ axial slices were produced with a $1.5 \mathrm{~mm} / \mathrm{s}$ interval of reconstruction with no intravenous contrast, $120 \mathrm{kVp}, 150 \mathrm{~mA}$, FOV (field of view) $20.1 \mathrm{~cm}$, and 512 x 512 matrix. The original data were transferred via network to an independent workstation (DELL Precision 420, Texas, USA) using Vitrea ${ }^{\circledR}$ software 2.3 version (Vital Images Inc., Plymouth, MN, USA) to obtain 3D$\mathrm{CT}$ images and to assess the calvaria and skull base, determining such craniofacial abnormalities as craniosynostosis and reduction of the anterior cranial fossa in the antero-posterior dimension.

One oral and maxillofacial radiologist, experienced in assessing craniofacial anomalies, analyzed the images regarding bone abnormalities. The clinical findings of the patients such as midface hypoplasia, turricephaly, brachicephaly, hypertelorism and exophthalmia, were also assessed, and then correlated to the CT findings. Other features, which were not found in the CT, such as syndactyly, cleft palate, midline pseudocleft palate, Byzantine arch-shape and bilateral palatal swellings were also evaluated and compared with the literature review.

\section{RESULTS}

The clinical assessment demonstrated that some manifestations such as symmetric syndactyly of the hands and feet, midface hypoplasia, hypertelorism, exophtalmia, palatal swellings producing a midline pseudocleft and tooth crowding were common findings in all patients. Cleft lip was found in one patient. The palatal Byzantine arch-shape was found in four of the five patients. The skull of all patients had increased height (turricephaly) and decreased length (brachicephaly) (Table 1).

3D-CT confirmed the clinical diagnosis in all patients and provided morphological topography of the abnormal skull and calvaria. Some abnormalities such as antero-posterior reduction of the anterior cranial fossa, antero-posterior reduction of the medial and posterior cranial fossa with an increase in their height were easily observed on 3D-CT (Figure 1).

Another feature seen in patients of our study was the wide midline calvarial defect (Table 2). This feature was found in four of the five patients and can be observed with no difficulty in the threedimensional reconstructions in a supero-inferior view (Figure 2). This midline defect in some cases was more prominent and extended to the glabellar 
area (Figure 3). Coronal bilateral symmetric synostosis was also present in all patients with Apert syndrome in the present study (Figure 2). This condition could change the calvarial shape and produce an abnormality such as brachicephaly and turricephaly.

The clinical findings were correlated to the CT images. Some abnormalities such as hypertelorism and exophthalmia were present in all of the patients in the clinical and CT examinations. Craniofacial abnormalities such as turricephaly, brachicephaly and midface hypoplasia were also visualized both in the clinical exam and on 3D-CT.

\section{DISCUSSION}

Apert syndrome is a developmental condition characterized by craniofacial and brain malforma- tions, midface hypoplasia, oral and ophthalmologic abnormalities, symmetric syndactyly of the hands and feet, and other visceral anomalies ${ }^{4,5}$. Many studies have shown either the clinical aspects or the imaging findings of the syndrome, but none have correlated their clinical findings with the features found on CT. For this reason, we proposed to perform the imaging correlation and determine the main abnormalities found in Apert patients.

Although rare, these disorders can have devastating effects on affected individuals as well as on their families. Affected individuals usually have a progressive worsening of the deformed craniofacial appearance and may develop blindness because of the exophthalmia. The orbits are shallow and the roof of the orbit is usually steep, causing exophthalmia. Ocular abnormalities, hypertelorism

TABLE 1 - Clinical findings of Apert patients.

\begin{tabular}{|c|c|c|c|c|c|c|c|c|c|c|c|c|}
\hline $\begin{array}{c}\text { Case } \\
\text { no. }\end{array}$ & Sex & $\begin{array}{c}\text { Age } \\
\text { (years) }\end{array}$ & Syndactyly & $\begin{array}{c}\text { Cleft } \\
\text { palate }\end{array}$ & Pseudocleft & $\mathrm{MFH}$ & CWT & HYPT & $\mathrm{EXPH}$ & TURRI & BRAC & $\mathrm{BYZ}$ \\
\hline 1 & $\mathrm{M}$ & 2 & Hands and feet & Absent & + & + & + & + & + & + & + & + \\
\hline 2 & M & 4 & Hands and feet & Absent & + & + & + & + & + & + & + & + \\
\hline 3 & $\mathrm{~F}$ & 4 & Hands and feet & Absent & + & + & + & + & + & + & + & - \\
\hline 4 & M & 4 & Hands and feet & Cleft lip & + & + & + & + & + & + & + & + \\
\hline 5 & $\mathrm{M}$ & 3 & Hands and feet & Absent & + & + & + & + & + & + & + & + \\
\hline
\end{tabular}

M (male); F (female); MFH (midface hypoplasia); CWT (tooth crowding); HYPT (hypertelorism); EXPH (exophthalmia); TURRI (turricephaly); BRAC (brachicephaly); BYZ (Byzantine arch); (+) present; (-) absent.

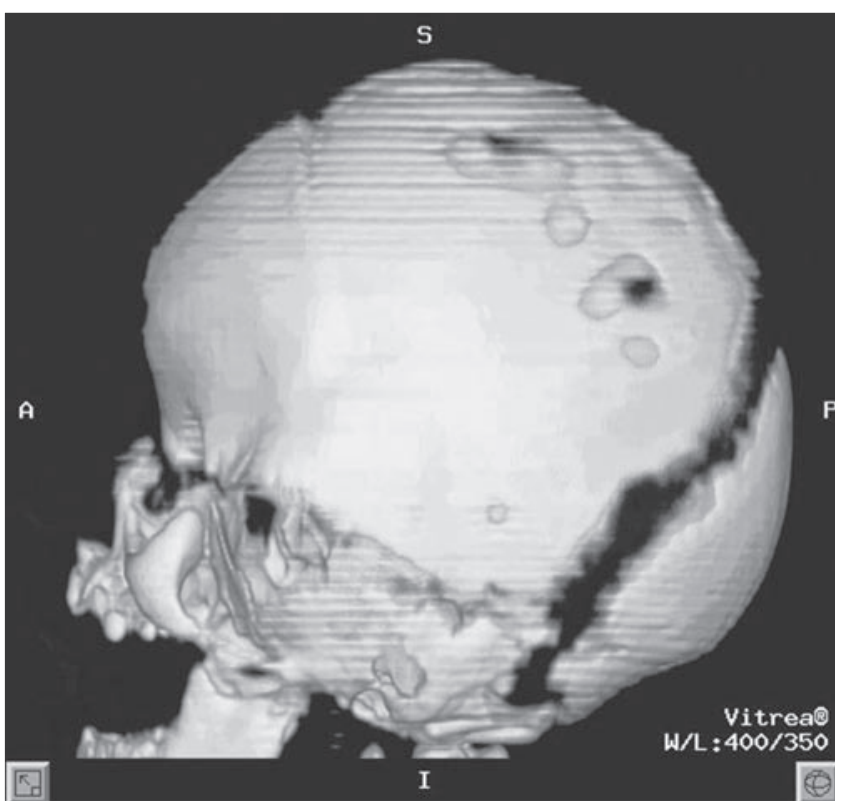

FIGURE 1 - Lateral view of a 3D-CT image demonstrating the brachicephalic and turricephalic shape of the Apert skull, and defects caused by immature and thin skull.

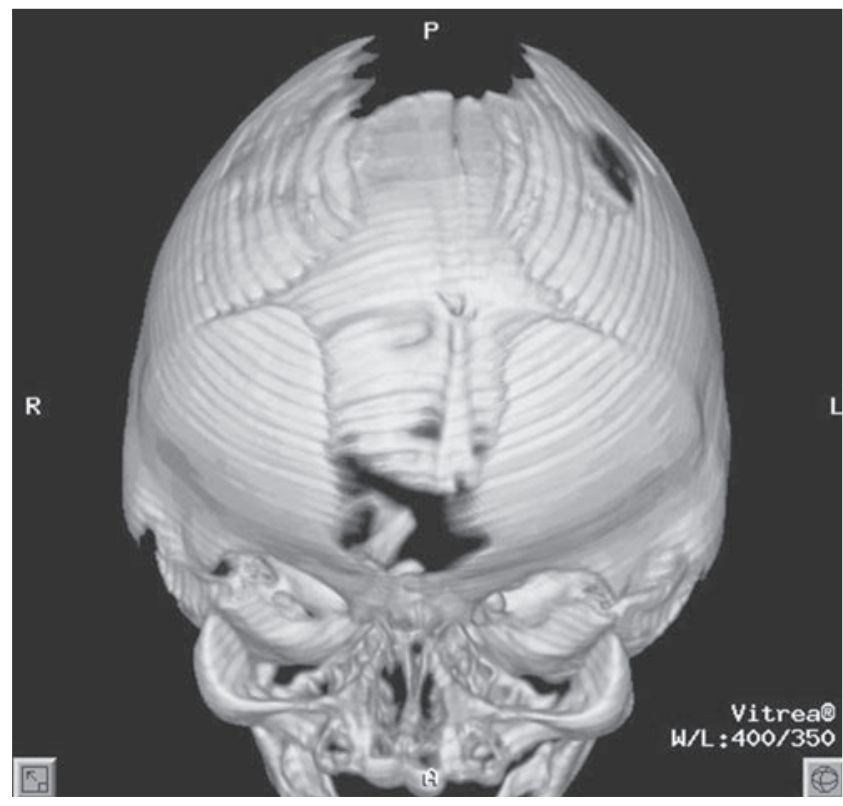

FIGURE 2 - 3D-CT image depicting the midline calvaria defect in Apert skull, and bilateral coronal synostosis. 
TABLE 2 - Assessment of the face, skull base and calvaria by 3D-CT.

\begin{tabular}{c|c|c|c|c|c|c|c|c|c|c|c|}
\hline \hline Case no. & DACF & DMCF & DPCF & COR syn. & SAG & HYPT & EXPH & MFH & TURRI & BRAC \\
\hline 1 & + & + & + & Bilateral & + & + & + & + & + & + \\
\hline 2 & + & + & + & Bilateral & + & + & + & + & + & + \\
\hline 3 & + & + & + & Bilateral & - & + & + & + & + \\
\hline 4 & + & + & + & Bilateral & + & + & + & + & + \\
\hline 5 & + & + & + & Bilateral & + & + & + & + \\
\hline \hline
\end{tabular}

DACF (decrease of the anterior cranial fossa-anteroposterior); DMCF (decrease of the medial cranial fossa-anteroposterior - increase in height); DPCF (decrease of the posterior cranial fossa-anteroposterior - increase in height); COR syn. (synostosis of the coronal suture); SAG (sagittal midline defect); HYPT (hypertelorism); EXPH (exophthalmia); MFH (midface hypoplasia); TURRI (turricephaly); BRAC (brachicephaly); (+) present; (-) absent.

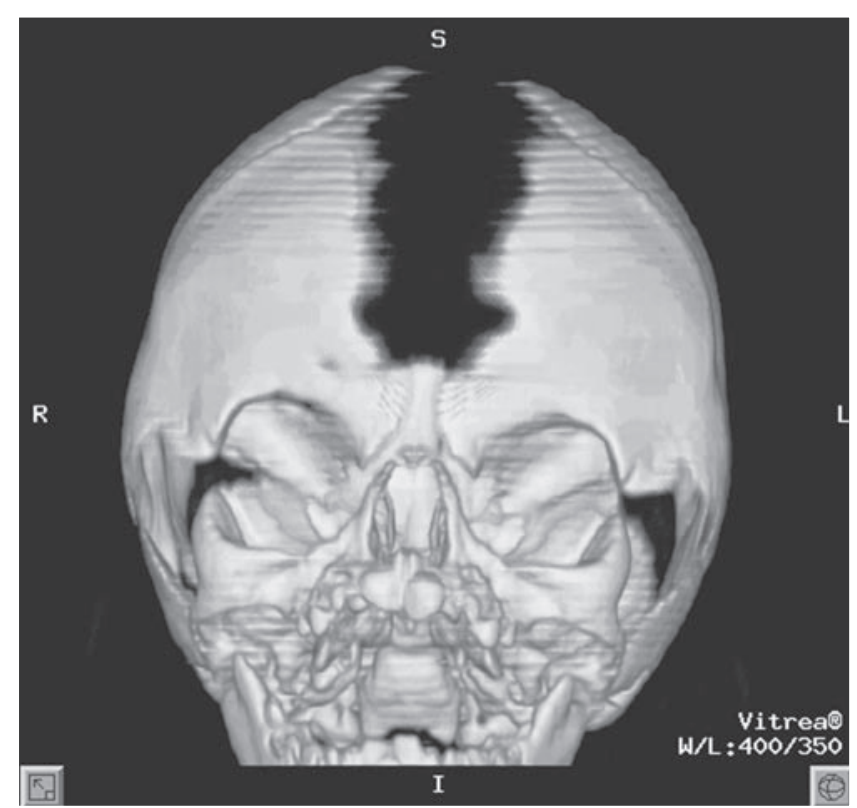

FIGURE 3 - Frontal view of 3D-CT shows the maxillary hypoplasia and the midline defect extending to the glabellar area.

and exophtalmia were observed in $100 \%$ of our patients.

According to Kreiborg and Cohen ${ }^{7}$ (1992), cleft palate and bifid uvula were found in approximately $75 \%$ of the cases. None of the patients in our study had cleft palate or bifid uvula. We found just one patient with superior cleft lip. A Byzantine arch-shaped palate was recorded in all of the patients in our study. According to Kreiborg, Cohen $^{7}$ (1992), this phenomenon becomes more pronounced with age and can produce a midline palatal pseudocleft that may be misdiagnosed as a true cleft. These swellings are characteristic of the Apert syndrome and have been shown to contain excessive mucopolysaccharides, predominantly hyaluronic acid, and to a lesser extent sulfated mucopolysaccharides ${ }^{13}$.

Another characteristic feature is the altered shape of the head with an increase of its height (turricephaly) and a decrease of its length (brachicephaly). This pattern was seen in all cases that we reported. Midface hypoplasia producing a pseudoprognathism was also observed in all of the patients. These abnormalities (Bynzantine archshape, bilateral palatal and midface hypoplasia) not only affect the esthetics of the patient but can also affect his/her respiration and speech ${ }^{11}$.

The craniofacial abnormalities were also reported as common findings in patients with Apert syndrome ${ }^{4,7,9,10}$. Kreiborg, Cohen ${ }^{6}$ (1990) analyzed skull radiographs of 16 Apert patients and found a bilateral premature fusion of the coronal sutures in all cases. Kreiborg et al. ${ }^{9}$ (1993) argued that the use of the term "craniosynostosis" for patients with Apert syndrome should be discouraged because no proper interdigitated suture formation ever takes place in the coronal area of the calvaria. In addition, since the coronal sutures are fused at birth, one cannot be certain whether simple coalescence of bone takes place during intrauterine life, or whether a "true pre-suture area" really develops 9 . The skull of Apert patients is immature and thin causing irregular defects in the calvaria ${ }^{9}$.

Kreiborg et al. ${ }^{9}$ (1993) analyzed Apert skull using 3D-CT images and reported that the calvaria in these patients are characterized by premature fusion of the coronal sutures. In the evaluation of Apert infants (0-1 year-old) they found an extensive midline calvarial defect from the glabellar area to the posterior fontanelle in all cases. Our results were in agreement with Kreiborg et al. ${ }^{9}$ (1993), since we also found, using 3D-CT, bilateral premature coronal synostosis in all patients, and the absence of an interdigitated suture formation. The sagittal midline defect was present in four of the five CT patients (Table 2). According to Kreiborg, 
Cohen $^{6}$ (1990), this happens because during the first 2-4 years of life the sagittal gap becomes obliterated by coalescence of the enlarging bony island without evidence of any proper suture formation.

Antero-posterior reduction of the anterior cranial fossa was reported by Kreiborg et al. ${ }^{9}$ (1993) in $33.3 \%$ of their patients. Our results demonstrated a higher incidence of this reduction (Table 2). We found that all Apert patients have a reduction of the anterior cranial fossa, and also found that this reduction extended to the medial and posterior fossa. The medial and posterior cranial fossae also presented an increase in height. These deformities of the skull shape are characterized by reduction of the cranial length - brachicephaly - and an increase in its height - turricephaly.

In the correlation of different examinations (clinical and CT) we showed that some abnormalities were demonstrated in all of them. Ophthalmologic anomalies such as hypertelorism and exophthalmia were seen in both exams. The altered shape of the skull could be assessed by clinical exam and by 3D-CT. Brachicephaly and turry-

\section{REFERENCES}

1. Byrd SE, Naidich TP. Common congenital brain anomalies. Radiol Clin North Am 1988;26:755-72.

2. Cohen MM Jr, Kreiborg S, Lammer EJ, Cordero JF, Mastroiacovo P, Erickson JD, et al. Birth prevalence study of the Apert syndrome. Am J Med Genet 1992;42:6559.

3. Cohen MM Jr, Kreiborg S. Cranial size and configuration in the Apert syndrome. J Craniofac Genet Dev Biol 1994;14:153-62.

4. Cohen MM Jr, Kreiborg S. The central nervous system in the Apert syndrome. Am J Med Genet 1990;35:36-45.

5. Holten IWR, Smith W, Isaacs JI, Moore MH, David DJ. Imaging of the Apert syndrome hand using three-dimensional CT and MRI. Plast Reconstr Surg 1997;99:167580.

6. Kreiborg S, Cohen MM Jr. Characteristics of the infant Apert skull and its subsequent development. J Craniofac Genet Dev Biol 1990;10:399-410.

7. Kreiborg S, Cohen MM Jr. Is craniofacial morphology in Apert and Crouzon syndromes the same? Acta Odontol Scand 1998;56:339-41.

8. Kreiborg S, Cohen MM Jr. The oral manifestations of Apert syndrome. J Craniofac Genet Dev Biol 1992;12:41-8.

9. Kreiborg S, Marsh JL, Cohen MM Jr, Liversage M, Pedersen H, Skovby F, et al. Comparative three-dimensional analysis of CT-scans of the calvaria and cranial base in Apert and Crouzon syndromes. J Craniomaxillofac cephaly were observed in the clinical exam and in the assessment of the 3D-CT. Hypoplasia of the midface is another change observed in the correlation of the clinical findings with the computed tomography findings.

We consider that the correlation of the clinical and 3D-CT findings allow several improvements in the diagnosis and management of patients with Apert syndrome. The value of 3D-CT images in the assessment of craniofacial malformations in Apert syndrome can be established and their widespread use can be adopted and encouraged.

\section{CONCLUSIONS}

We have shown that Apert syndrome is a severe craniofacial dysostosis, with complex involvement of the face, calvaria and skull base. The combination and correlation of clinical evaluation and $3 \mathrm{D}-\mathrm{CT}$ imaging can be useful to assess the main abnormalities observed in Apert syndrome. It allows a more complete assessment of patients, supplying relevant information for the diagnosis, therapeutic planning and surgical outcome.
Surg 1993;21:181-8.

10. Pavaratty RP, Ahsan A, Sebastian BT, Pai KM, Dayal PK. Apert syndrome: a case report with discussion of craniofacial features. Quintessence Int 1999;30:423-6.

11. Peterson SJ, Pruzanski SP. Palatal anomalies in the syndromes of Apert and Crouzon. Cleft Palate J 1974;11:394 403.

12. Renier D, Arnaud E, Cinalli G, Marchac D, Brunet L, Sebag G, et al. Mental prognosis of Apert syndrome. Arch Pediatr 1996;3:752-60.

13. Solomon LM, Medenica M, Pruzansky S, Kreiborg S. Apert syndrome and palatal mucopolysaccharides. Teratology 1973;8:287-92.

14. van der Knaap MS, Bakker CJ, Faber JA, Valk J, Mali WP, Willemse J, et al. Comparison of skull circumference and linear measurements with CSF volume MR measurements in hydrocephalus. J Comput Assist Tomogr 1992;16:73743.

15. Vannier MW, Hildebolt CF, Marsh JL, Pilgram TK, McAlister WH, Shackelford GD, et al. Craniosynostosis: diagnostic value of three-dimensional CT reconstructions. Radiology 1989;173:669-73.

16. Vannier MW, Pilgram TK, Marsh JL, Kraemer BB, Rayne $\mathrm{SC}$, Gado $\mathrm{MH}$, et al. Craniosynostosis: diagnostic imaging with three-dimensional CT presentation. AJNR Am J Neuroradiol 1994;15:1861-9. 